\title{
Sokak köpeklerinin üst solunum yollarından Bordetella bronchiseptica izolasyonu
}

\author{
Jale ERDEĞER
}

Ankara Universitesi. Veteriner Fakiultesi. Mikrobiyoloji Anabilim Dalı. Ankitra

\begin{abstract}
Özet: Köpcklerin infeksiyöz trahcobronşitisinin (ITB) primer etkeninin Bordetella bronchisepticu olduğ bildirilunckledir. Bu

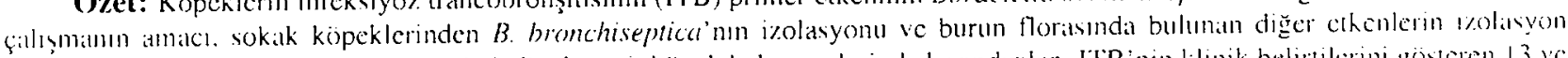

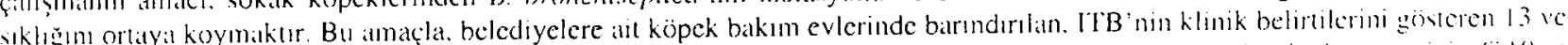
să

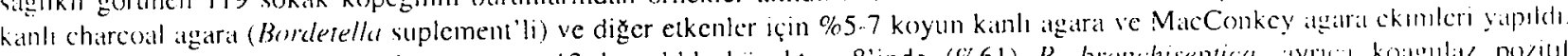

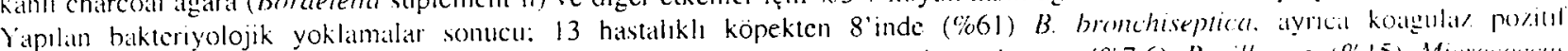

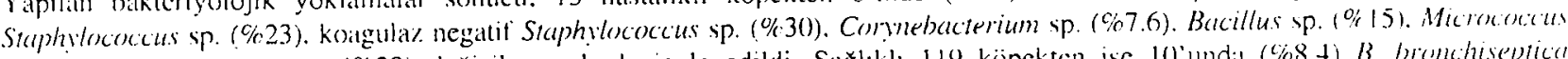
sp. (\%7.6) ve Proteus sp. (\%23) desisik oranlarda izole edildi. Sioglıklı 119 köpekten ise 10) izoliuyonu gerçcklcş̣irildi. Sonuç olarak, sok:ak köpeklerinin solunum yolu infeksiyonlarmmn predominam akenunin $B$. brenchiseptica olduxu kimmsinat varulds.
\end{abstract}

Anahtar kelimeler: Bordetella bronchiseptica, infeksiyoz. traheobronşitis (ITB), izolisyon. kopek

\section{Isolation of Bordetella bronchiseptica from upper respiratory tracts of stray dogs}

Summary: Bordetella bronchiseptica is regarded as the primary agent of canine infectious watheobronchims (ITB). The alull of this study was to isolate B. bronchiseptica from stray dogs and to determine the isolation frequency of other bacterial agents logether with B. bronchiseptica that might possibly be present in the nostril tloria. For this purpose. swabs were tithen from the mostrils of 13 dogs that had clinical manifestations of ITB and 119 apparently healthy dogs. that were kept in municipal kemncls Swath amples were culured on $10 \%$ horse blood charcoal agar (with Berdetella suplement) for the isolittion of B. brome.hiseptica. and on $5.7 \%$ sheep blood igatr and MacConkey agar for the isolation of other bacteriat agents. Bacicriological eximninallion revealed that B. hirenchiseptica wals isolited from 8 of 13 diseased dogs $(61 \%)$. with the isolation of other bacterial algente with varying

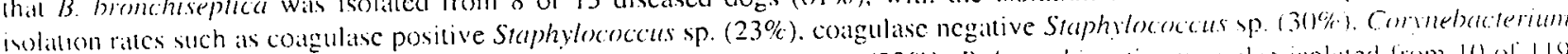
sp. (7.6\%). Becilless sp. (15\%). Micrescoccus sp. (7.6\%) and Proteus sp. (23\%). B. hronchiseptica was allso isolated from 10 ol 119 atpatenty healthy doss $(8.4 \%)$. It was concluded that $B$. bronchiseptica was the predominant agent responsible from revpiation tract infections of stray ciogs

Key words: Bordetella hronchisepfica dog, infectious tracheobronchitis (ITB), isolation

\section{Giriş}

Bordetella bronchiseptica. köpeklerin önemli bir solunum yolu infeksiyonu olan infeksiyöz traheobronsitisinin primer eıkeni olarak kabul edilmektedir (4,9.11). Köpek gençlik hastalığı ile birlikıe seyrettiği düşünülen ITB. guinuinuizde ayrı bir hastalık durumu olarak degerlendirilmekledir (4.11). B. bronchiseptica. köpeklerin iist solunum yollarmda kommensal bir etken olarak bulunahilir (14.19). Elken, solunum yolu infeksiyonu olan kopeklerin nazolarinksinden siklskla izole edilmekledir (14.17). Ayrica, insanlarda yara ve vijcut sivilarindan da izole edilmekte ve huna bağ ll olarak zoonotik infeksiyon olduğu lahmin cdilnekıcdir (14).

B. bronchiseptica, Bergey's Manual of Systematic Bactcriology (1984) yc görc Gram negatif. aerobik çomak ve koklar grubunda Neisseriaceac familyası içinde yer almaktadır (13). Etkenler Gram negatif, hareketli (pe-

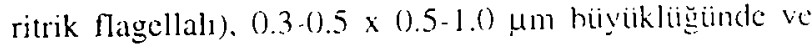
mikroskobik bakıda kokobasil seklindedir (6.10.14). Viruilent suşlar piluslu olup. ekstrassellular enzim olarak ade nilat sikla\% sente $\%$ ler. Mikroorganizmal taralindan genetik kontrol altunda sentezlenen dernonckrolik loksin. pronteazlar, hemolizin ve hemaglutininler inleksiyonun pat. logenezisinde önemli rol oynamakladır (7.11.14).

Viruslar direkt olarak veya viral hakleriyel sinergizm ile ITB nin eliyopatogenezini clkilentekle ancalk. hastalığın oluşumundaki ełkinlikleri kessin warak hi linmemektedir. Bu viruslarm canine paranlluenzal virus (CPIV), canine adenovirus type ? (CA V -2). canine herpes virus ve revirus olduklar lahmin colihnektodi $(11,16,19)$

Yapulan bazı araşurmalarda B. brenchiseptica Mycoplasma ve diğer viral etken]er olmaksım [TB ye neden olduğu saptanmışur $(11,16)$. Bemis ve ark. (5). 
SPF köpcklercic B. bronchiseptica'nm acrosol yolla ITB ye neden olduğunu bildirmişlerdir. Bu verilere dayallarak araştırıcılar infeksiyon sonucu oluşan bağışıklık ve etkenin organlardan izole edilebilmesine bağls olarak. mikroorganizmanm infeksiyonda primer olarak rol oynadığı önc sürmuişlcrdir. Thompson ve ark. (17), pneumonili köpeklerden i\%ole edilen B. bronchiseptica ile acrosol yolla infekte edilen 6-12 haftallk köpeklerde ve ayncia kontakt yolu ile infekte edilenlerde öksürük ve bazı olgularda purulent burun akıntısı saptamışar ve B. bronchiseptica. burun hoşluğ u, trahea, bronşlar ve akciğgerden salf kuiltiir halinde izole edimiştir. Traheal svablardan izolasyonlar alt solunum yolu infeksiyonlarmm daha kesin hir göslergesi olarak kabul edildiği halde, Bemis ve ark. (4). yapukları f̧alışmada. B. Iron-chiseptica'nır nazal svablardan da güvenilir bir şekilde izole edilebileceğini bildirmişlerdir. Gerhardı ve ark. (8), 5 kronik traheobronşitisli köpekle, relrospektif bir çalışma yaparak. tiim vakalardan $B$. hronchiseptica izolc ettiklerini açılamustar, araștuncular $B$. bronchiseptica' nun genç köpeklerde kronik traheobronşitis ve ciddi solunum yolu hastahığına neden olduğumu bildirnişlerdir. Batcy ve ark. (3). bit pneumoni salgınında, köpcklerin farengcal svab. akciğer ve cksudatlarndan B. bronchiseptica'yı saf olarak izole ettiklerini: Ueland (18) ise, 1988 yllında Norveç le ITB salgumnda, klinik belirti gösteren 66 köpckten aldığ 1 boğ:az svablarından yapuğı bakteriyolojik incolenelerde $B$. bronchiseptica izole edememiştir. Araşturicr. Staphylococous sp., Enterobacter sp., E. coli, Pseudomonas sp. Acinetobacter sp.. Streptococcus sp. vo Klehsiella sp. elkenlerinin izole edildiğini bildirmiştir.

Angus le ark. (1), 1989-1995 yilları arasinda yapıkları araşurmada, solunum yolu infeksiyonu görülen 264 köpekten transtraheal aspirat alnışlar ve yaptıkları bakleriyolojik incelemede \%45.7 orannda Enterobacteriaceinc fanılyasma ait turler (özellikle $E$. coli) izole etmişlcrdir. Bu bulguları Pasteurella sp. (\%22.4). obligat anaeroblar (\%21.6), $\beta$-hemolitik Streptococcus $\mathrm{sp}$. (\%12.1). B. bronchiseptica (\%12.1), non-hemolitik Streptococcus sp./ Enterococcus sp. (\%12.1), koagulaz pozitif Staphylococeus sp. (\%9.5) ve Pseudomonas sp. (\%7.8) i\%olaısyonlammon i\%lediğini aç̧klamışardır. Balish ve ark. (2). kapalı ve açık ortamda bulunan köpeklerin nazal florasm incelediklerinde: aerobik ve lakültatif anaerobik mikroorganizmalardan en yaygun olarak Stuphylococcus epidermidis. Streptococcus mitis. S. salivaras ve Acinetobater calcorceticus subsp. Iweffi yi izole etmişlerdir.

Maden ve ark. (12), solunum yolu hastalığ belirtileri gristeren 25'i hasta ve 6'sı sağlıklı 31 köpekten aldıklan bronkoalveolar livaj (BAL) sıvılarında yapmış ol- dukları mikrobiyolojik incelemede: $B$. bronchiseptica ve E. coli (\%24) başta olmak ürere. Pastentellu sp.. koagulaz pozitif Staphylococcus sp. ve Corvnehacterium sp. (\%12); Pastearella haemolytica ve Enterobater sp. (\%.8)

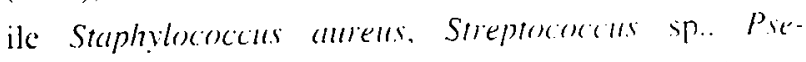
udomomas sp. Bacillus sp.. Proteus sp. ve Klebriella sp. (\%4) izole etmişlerdir.

Bu çalışmanın amacı. solunnum yolu inleksigunnu kli. nik belirtileri gösteren hastalıklı ve klinik belinti gö̈stermeyen sağlıklı köpeklerden B. brenchiseptica'nun izo. lasyonunu yapmak. B. bronchiseplica'num ve köpeklerin burun florasında bulunan diğer elkenlermin izolasyon sık Iığını ortaya koymakır

\section{Materyal ve Metot}

\section{Burun svabları}

Belediyelere ait köpek bakımevlerinde toplamms olan, ITB'nin klinik belirtilerini gösteten hastalıklı (1,3 adet) ve klinik belirti göstermeyen sağhkh (119 adel) sokak köpeklerinden svabiarla, burundan maleryal alındı. Burun svabları Amies Transport Medium içerisinde. soğuk zincirle $\left(+4^{\circ} \mathrm{C}\right)$ laboratuvara ulasşurılds.

\section{Besi yerleri}

B. bronchiseptica izolasyonu için. \%10 al kanh. charcoal agar (CM119-Oxoid) kullanild. Charcoal agara Bordetella selective suplement (SR82 Oxorid) ilare edildi (15). Aynca, B. bronchiseptica'nun ve diger ckenterin izolasyonu amaciyla \%5-7 koyun kiunl agar ve MacConkey agar kullanıldt.

\section{Izolasyon ve identifïkasyon}

Burun svaplarndan $\% 10$ at kanls charcoal sefaleksin agara. \%5 7 koyun kanl agar ve MacConkey agara ekimler yapıld. Besi yerleri aerohik koşullarta. $37^{\circ} \mathrm{C}$ 'de, 24-48 saal inkube edildi. Üreyen kolmikrin makroskohik görüuümleri değerlendirildi. Yole edilen elkenlerin identifikasyonu bilinen yöntemlere göre yapıld $(4.7 .13 .16)$.

\section{Bulgular}

Yapilan bakteriyolojik yoklamalar sonucu. ITB inin klinik bulguların gösteren 13 köpeğin 8 inden $(\% / 61)$. klinik bulgu göslerneyen 119 köpeğin 10$)^{\prime}$ undan (\%.8.4) B. bronchiseptica izole edildi, Loplam olarak 132 sokak köpeğinin 18'inden (ć1.3.6) bu eckenin irolalsyonu gerçckleştirildi. Materyallerin alındığ yer ve inolasyon oran lanı Tablo l'de gösterilmişır. B. hronchiseptica dı̧̧ında izole edilen diğger nikroorganizmalar. I'TB' nin klinik bulguların gösteren 1.3 köpekten 3’ünde (\%.23) keragulà pozitif Suphylocoecus sp., 4'ünde (\%30) kogulà negant 
Staphylecocens sp. 1 inde (\%7.6) Corynebacterium sp.. 2 sinde (\%15) Bacillus sp. I Inde (\%.7.6) Micrococeus sp.. 3̈unde (\%:23) Proterts sp. 'djr. Klinik bulgu göstermejen sokak köpeklerinden izole edilen diğer mik- roorganizmalar ise yukarıda bildirilenlerle birlikle. Strepucoccus sp., E. coll. Acinetohacter sp. Akcaligenes sp. Pasteurella sp. Hatemophilus sp.. Mormella sp. Veisseria sp. Klebriella sp.. Promeas sp.. Preadmmonas sp.

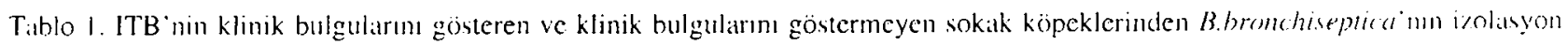
sitylsi ve oranlarn (\%).

Tible 1. Isolation numbers and rates (\%) of B.bronchiseptice from stray dogs with and without clinical manifestattions of ITB

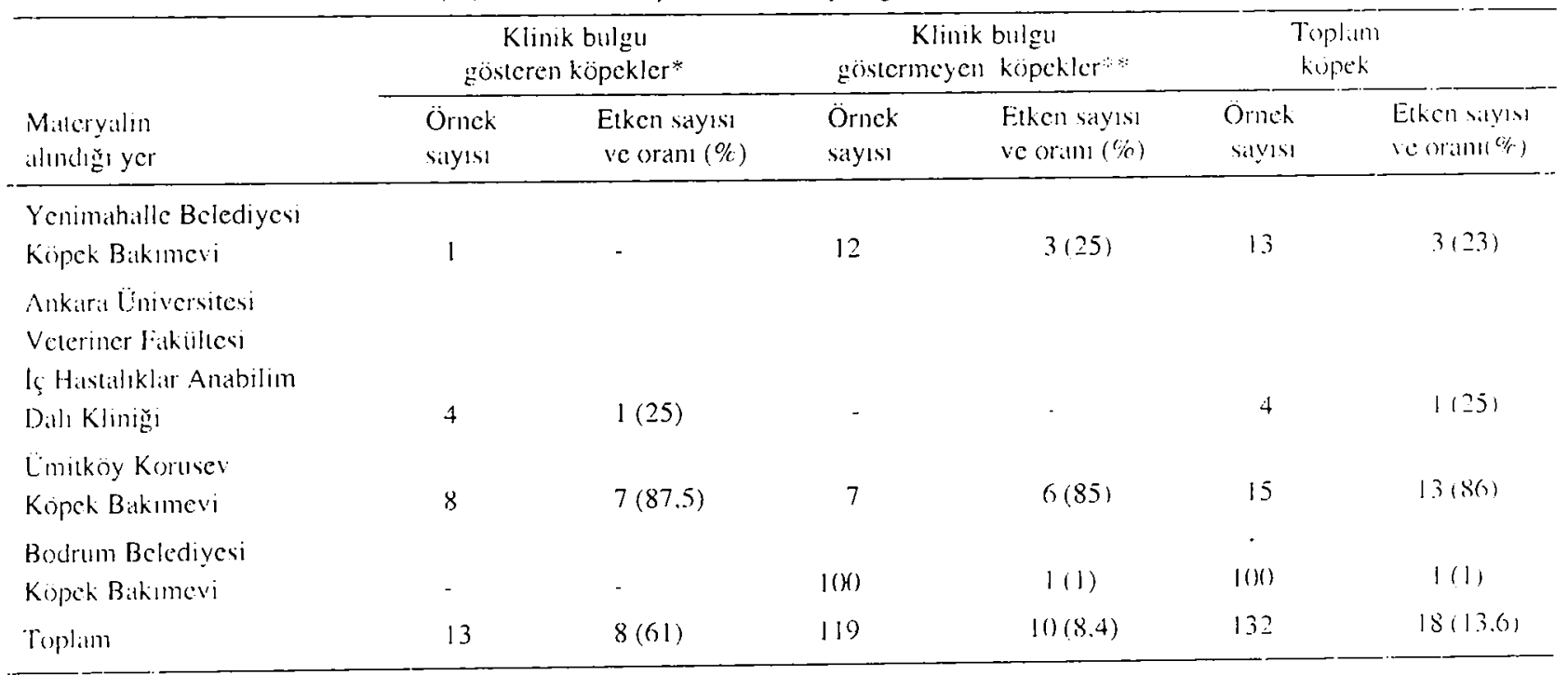

[TB nin klinik bulgularmont (öksiririk. burun akıntısı vh.) göstcren köpekler

Klinik olar ak sičclıklı görïnen köpekler

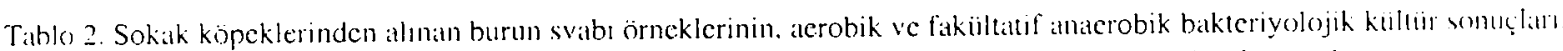
Table 2. Acrobic and ficultative anacrobic culture results of swab samples obtamed from nostrils of stray dogs.

\begin{tabular}{|c|c|c|c|c|c|c|}
\hline \multirow[b]{2}{*}{ Mikroorganizma } & \multicolumn{2}{|c|}{$\begin{array}{c}\text { Klinik bulgu } \\
\text { gösteren köpekler * }\end{array}$} & \multicolumn{2}{|c|}{$\begin{array}{c}\text { Klinik bulgu } \\
\text { gösterneyen köpekler :s: }\end{array}$} & \multicolumn{2}{|c|}{$\begin{array}{l}\text { Toplann } \\
\text { köpck }\end{array}$} \\
\hline & $\begin{array}{l}\text { lzolat } \\
\text { sily1si }(\%)\end{array}$ & $\begin{array}{r}\text { Örnek } \\
\text { sayısı }\end{array}$ & $\begin{array}{l}\text { lzolat } \\
\text { sayıss (\%) }\end{array}$ & $\begin{array}{l}\text { Örnck } \\
\text { sayss }\end{array}$ & $\begin{array}{l}\text { l\%olat } \\
\text { Silym }(\%)\end{array}$ & $\begin{array}{l}\text { Ornek } \\
\text { silyisi }\end{array}$ \\
\hline B. Hronchiseptica & $8(61)$ & 13 & $10(8.4)$ & 119 & $18(13.6)$ & 132 \\
\hline Koigulaz pozilif & & & & & & \\
\hline 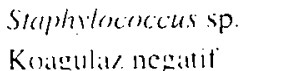 & $3(23)$ & 13 & $49(41.1)$ & 119 & $52(34.3)$ & 1.32 \\
\hline 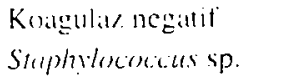 & & & & & & \\
\hline 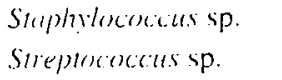 & $4(3(1)$ & 13 & $36(30.2)$ & 119 & 4()$(30.3)$ & 1.32 \\
\hline $\begin{array}{l}\text { Streptrococous sp. } \\
\text { Comyelouterium sp. }\end{array}$ & - & 13 & $5(4.2)$ & 119 & $5(3.7)$ & 1.32 \\
\hline $\begin{array}{l}\text { Compelacterium sp. } \\
\text { Bacillus sp. }\end{array}$ & $1(7.6)$ & 13 & $2(1.6)$ & 119 & $3(2.2)$ & 1.32 \\
\hline $\begin{array}{l}\text { Bacillus sp. } \\
\text { Micmernccus sp. }\end{array}$ & $2(15)$ & 13 & $14(11.7)$ & 119 & $10(12.1)$ & 1.32 \\
\hline Micmenceles $p$. & $1(7.6)$ & 13 & $12(10)$ & 119 & $13(9.8)$ & 132 \\
\hline licoli & - & 13 & $16(13.4)$ & 119 & $16112,1)$ & 1.32 \\
\hline Acthetrbacter sp. & - & 13 & $9(7.5)$ & 119 & $9(6.8)$ & 1.32 \\
\hline Alcaligenes sp. & - & 13 & $4(3.3)$ & 119 & $+(3)$ & 1.32 \\
\hline Pasteturellasp. & - & 13 & $19(15.9)$ & 119 & $19(14.3)$ & 1.32 \\
\hline Hasmosphilus sp. & - & 13 & $2(1.6)$ & 119 & $2(1.5)$ & 1.32 \\
\hline Moratellasp. & - & 13 & $3(2.5)$ & 119 & $3(2.2)$ & 132 \\
\hline Veissertatsp. & - & 13 & $12(10)$ & 119 & $12(9)$ & 1.32 \\
\hline Kletosiella sp. & - & 13 & $2(1.6)$ & 119 & $2(1.5)$ & 132 \\
\hline Pioletas sp. & $3(23)$ & 13 & $16(13.4)$ & 119 & $19(14.3)$ & 1.32 \\
\hline Pseredommoncess sp. & - & 13 & $2(1.6)$ & 119 & $2(1.5)$ & 1.32 \\
\hline Milyal & & 13 & $23(19.3)$ & 119 & $23(17.4)$ & 1.32 \\
\hline
\end{tabular}

ITB nin klinik bulgularmu (öksuirik, burun akuntusı vb.) gösteren köpekler

Klinik olatrak salds lıkle görrïnen köpekler 
ve malya dr. Klinik bulgu gösteren. klinik bulgu göstermeyen ve toplam olarak lïm sokak köpeklerinden alınan hurun svaplarndan izole edilen acrobik ve faküitatif anacrobik bakterilerin salyı ve oranları Tablo 2 de verilmiştir.

\section{Tartışma ve Sonuç}

Köpeklerde solunum yolu infeksiyonuna neden olan etkenler arasinda siklıkla izole edilen B. bronchiseptica, ITB infeksiyonunun primer ajan olarak kabul edilnekledir (4.9.11.17). Bu olgu yapilan dencysel inficksiyonlarla (11.14.17) araştunclalar larafindan ortaya konulmuşutur. Bemis ve ark. (4) B. bronchisepticainın hunundan alman örncklerden kolaylıkla izole edilchilecegini. bireysel olarak beslenen 95 köpekten $81^{\prime}$ inde, grup halinde tutulan 115 köpekten $69^{\circ}$ unda $B$. bronchiseptica jzole ettiklerini açıklanuşlardır. Gerhard ve ark (8). 5 kronik traheohronşitisli köpekte $B$. bron(hiseptica saptamışlardır ve etkenm genç köpeklerde kronik traheobronşitis ic ciddi solunum yolu haștalığına neden olduğ bunu bildirmişlerdir. Batey ve ark. (3), bir pneumoni salgımında köpeklerin farengeal svab, akciğer ve eksudatlarndan $B$. bronchiseptica'nın saf kültürünü elde elmişlerdir

Bu çahş̧mada. ITB'nin klinik belirtilerini gösteren 13 sokak köpeğginden 8 inde (\%61) B. bronchiseptica irole edilmiştir. Bu olgular, diğer araşurıciların bulgularms destekler nitclikledir ve $B$. bronchiseptica' nm kirpeklerde solunum yolu infeksiyonlarına neden olabileceğine işaret(ir. Ancak. bu çalışmada, klinik bulgu saptanmayan. sağglılı görinuimlï 119 köpeğin burun svablarmon 10'unda (\%8.4) B. bronchiseptica sapLanmışır. Bu. B. bronchiseptica'nın sağlıkh köpeklerin iist solunum yollarmonda kommensal olarak bulunabilmesi ile açıklanabilir.

Ueland (18), Norveç'leki bir köpek ITB salgımında, klinik belirti gösteren 66 köpckten aldığı boğa\% svaplarundan yapuğı baktcriyolojik incelemelerde, $B$. bronchiseptica izole edenemiş. köpeklerin \% $\%$ 7'sinde spesilik olmayan flora saptimışur. Araşurıcı. dominant türler olarak Staphylococcuss sp.. Enterobacter sp., E. coli. Pseudomonas sp.. Acinetobacter sp. Streptococeass sp. ve Klehsiella sp. jzole cmiştir. Ayrica, boğazdan alıuan örneklerden $B$. bronchiseptica izolasyonunun, nazal veya traheal svablardan daha az olduğunun da bildirildiğini belirtmiştir. Angus ve ark (1), alt solunum yolu hastalığ gösteren 264 köpekıen transtraheal aspirat almışlardır ve yaptıklan bakleriyolojik incelemede, örneklerin \%45.7' sinden Enterobacteriaceae fanilyasma ait tïrler iözellikle $E$. coli). \%22.4'unden Pasteurella sp. \%21.6'sindan zo- runlu anaeroblar, \%12. I'inden $\beta$-hemolitik Streptococects sp., \%:12.1'inden B. bronchiseptica. \%12.1'inden nonhemolitik Streptococcus sp./Enterocorcus sp. \% $\% 9.5 \mathrm{ko}$ agulaz pozitif Staphylococcus sp. ve $\%, 7.8$ Psemdommonas sp. izolasyonu yapmışlardır. Balish ve ark. (2), kapalı ve açık ortanda buhunan köpeklerin nakall florasımı incelediklerinde. aerobik ve fakiillatil analerobik mik roorganizmalardan en yaygun olarak Stophylecoccus epidermidis, Streptococcus mitis. S. sedivarts ie Acinetobacter calconaticas subsp. Iwoffi yi izole emmislerdir. S. curreus ve $A$. calconceticus subsp. anitratus izolasyonlars diğgerleri kadar sık değgildir. Araşurmada Microrencens luteas, Klebsiella pneamoniae. Compehaterim sp.. No cardia asteroides. Flavobacteriam sp. Bacillus subtilis. Lactohacillus sp. ve maya kapah ortandaki köpeklerden izole edilmiş, fakat açıktaki kontrol köpekklerden i\%ole edilmemiştir. Maden ve ark. (12). solunum yolu hastalığ belirtileri gösteren 25'i hasta ve 6`sı sağlıklı 31 köpeklelu aldıkları BAL sıvilarmda yapmıs olclukları nık robiyolojik incelemede; $B$. bronchiseptica ve $E$ coli (\%24) başı olnak ïzere, Pastemrella sp.. koagula\% pozitif Staphylococcus sp. ve Corynebucterimm sp. (\%12). $P$. haemolytica ve Enterohacter sp. (Cs) ile S. aureus. Streptococcuss sp.. Pseadmmonas sp.. Bacillus sp.. Parteus sp. ve Klebsieller sp. (\%:4) izole cmişerdir.

Bu çalışmada, ITB' nin klinik bu]gularm gösteren 13 köpckten, koagulaz pozitif Stuphylecocens sp. (\%23). koagulaz negatif Staphylococcus sp. (\%30), Comnebacterium sp. (\%7.6). Bacillus sp. (\% 15). Microcoscus sp. (\%7.6) ve Proteus sp. (\%,23). klinik bulgu gös termeyen 119 köpekien ise koalgulak pozitif $S t u p h$. lococcus sp. (\%41.1). koagulaz negalil Staphylococous sp. (\%30.2), Streptococcus sp. (\%4.2). Complehon ferimm sp. (\%1.6). Bacillus sp. (\%11.7). Microncoectus sp. (\%.10). E.coli (\% 13.4). Acinetobacter sp. (\%7.5). Alcaligenes sp (\%3.3), Pastearella sp. (\%15.9). Haemophilus sp. (\%) 1.6$)$ Moraxella sp. (\%2.5), Neisseria sp. (\%10). Klebriella sp (\%1.6), Proteus sp. (\%13.4). Psetudomomas sp. (\%1.6). maya (\%19.3) izole edilmiştir. Köpcklerin solunum yol larmdan izole edilen etkenlerin izolasyon manları. araş urmalardaki köpeklerin bulunduklan ortama göre litk llık göstermektc ve larklı bölgelerden latklı oranlarda izole edilmektedirler. Ayraci, i\%olasvon materyalinin alın-

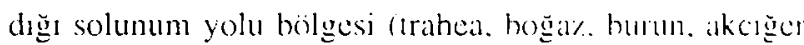
vs.) de izole edilen elkenler ve izolasyon oranlar izzrinde etkili olmakladır.

Sonuç olarak, bu araşurmada. klinik solunum yolu hastalığı teşhisi konulan köpeklerin çoğundan salf olarak izole edilen $B$. bronchireptica' nun köpeklerdeki solunum 
yolu hastalıklarında sık rastlanılan bakteriyel patojen olduğu kanısına varıldı. Ayrıca, diğer etkenlerin de izolasyonlarmun ve izolasyon oranlarının köpcklerin barndikları orlana, coğrafïk bölgeye ve materyalin ahındığ solunum yolu bölgesine bağ ollarak değişebileceği sonucuna varılds.

\section{Kaynaklar}

1. Angus CA, Jang SS, Hirsh DC (1997): Microbiolegical study of aranstracheal aspirates from dog.s with suspected Inwer respiratory tract disease: 264 cases (1989-1995). JA VMA. 1. 55-58.

2. Balish E, Cleven D, Brown J, Yale CE (1977): Nose, throul, and fecal flora of beagle dogs housed in 'locked" or 'open' enviromments. Appl Environ Microbiol. 34, 2(1)7221.

3. Batey RG, Snits AF (1976): The isolation of Bordetella bronchiseptica from an oubreak of canine pneumomiae. Aust Vel J. 52, 184-186

4. Bemis DA, Carmichael IJE, Appel MJG (1977): Naturally accuring respiratory disease in a kennel caused by Burdetella bronchiseptica. Comell Vet, 67, 282-293.

5. Bemis DA, Greisen HA, Appel M.JG (1977): Patho"uenesis of canine bordetellosis. J Infect Dis. 135. 753-762.

6. 13isping W, Amtsberg G (1988): Farbatlas zur Diagnose Baklerieller Infektionserveger der Tiere. Paul Parcy Scicntific Publishers, Berlin.

7. Carter GR, Chengappa MM, Roberts AW (1995): Bordetella and Moratella. Essentials of Veterinary Microhiology: Filth ed. William and Wilkins. Baltimore.

8. Gerhardt A, Gaschen F, Lang J, Bolliger AP (1997): Nachwies ron Borderella bronchiseptica im zusammen. hano, mit chromischer tracheobronchitis beun junghund. Ticrars.11 Prix. 25. 525-531.

9. Goodnow RA, Causey SC, Geary SJ, Wren WS (1983): Comparison of an infective avirulent and canine virulent Bordetella bronchiseptica. Am J Vet Res, 44, 207-211.
10. Holt JG, Krieg NR, Sncath PHA, Stalcy .TT, Willians ST (1994): Bergey's Manual of Deserminative Baceseriolegy: Nineth ed. William and Wilkins. Batlimore.

11. Keil DJ, Fenwick B (1998): Role of Bordetellet hromehiseptica in infections tracheabronchins in des:s JAVMA. 212, 2(0)-2(1).

12. Maden M., Birdane FM, Alkan F, Hadimli HH, Sen I.

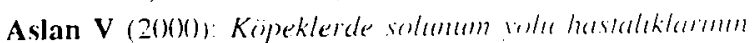

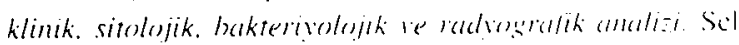
çuk Univ Vet Fak Derg. 16. 43-50

13. Pittman M (1984): Bordetella. 388-393 In: NR Kricg. JG Holt (Eds). Bergey's Manual of Systemittic Bacteriology. Williams and Wilkins. Baltimore.

14. Quinn PJ, Carter ME, Markey BK. Carter (;R (1994):

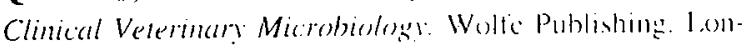
don.

15. Regan J, Lowe F (1977): Eimrithene medium for the tist lation af Bordetella. J Clin Microbiol. 6. 303-3(1)

16. Roop RM (199(1)): Bordetella and Alcalisuenes. 87-94. Wh: GR Carter. JR Cole (Eds). Ditignowlic Procedures in Vcterinary Bacteriology and Mycology. Filth ed. Acidemic Press, San Diego.

17. Thompson H, McCanlish AP, Wright N( 11976): Li.

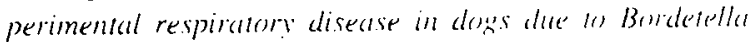
bronchiseptica. Res Vot Sci. 20. 16-23

18. Ueland K (1990): Serolegical. Pacterological and clincal observations on an outhreak of canne infectimas tracheohronchitis in Norwal. Vat Rec. 126. $481-483$.

19. Wagener JS, Sobonya R, Minnich I.. Taussig IsM (1984): Role of canine parainfluenad virus and Bordetella bronchiseptica in kennel cough Am J Var Res. 45. 186?1866

Gelis tarihi: 26.10.2001/Kabut wriht 27.12.2(k)1

Yazışma adresi:

Doş.Dr. Jale Erdeğer

Ankara Üniversitesi. Veteriner Fakiiltesi

Mikrobivoloji Anabilim Dale

O6110 Diskapu Ankata 